\title{
Divulging the Intricacies of Crosstalk Between NF-Kb and Nrf2-Keap1 Pathway in Neurological Complications of COVID-19
}

\author{
Ranjana Bhandari $^{1} \cdot$ Garima Khanna $^{1} \cdot$ Dhriti Kaushik $^{1} \cdot$ Anurag Kuhad ${ }^{1}$ (D) \\ Received: 8 January 2021 / Accepted: 25 February 2021 / Published online: 8 March 2021 \\ (C) The Author(s), under exclusive licence to Springer Science+Business Media, LLC, part of Springer Nature 2021
}

\begin{abstract}
The severity of COVID-19 infection is surging day by day. With the cases increasing daily, it is becoming more and more essential to understand the pathogenic mechanisms underlying the severity of the disease. It is now well known that the infection manifests itself primarily as respiratory, but the involvement of the other organ systems has now been documented in many studies. SARS-CoV-2 can invade the nervous system by a multitude of proposed mechanisms that have been discussed in this review. NF- $\mathrm{KB}$ and Nrf2 are transcription factors that regulate genes responsible for inflammatory and anti-oxidant response respectively. Specific focus in this review has been given to NF-KB and Nrf2 pathways that are involved in the cytokine storm and oxidative stress that are the hallmarks of COVID-19. As the immune injury is an important mechanism of neuro-invasion and neuroinflammation, there is the possible involvement of these two pathways in the neurological complications. The crosstalk mechanisms of these signaling pathways have also been discussed. Immuno-modulators both synthetic and natural are promising candidates in catering to the pathologies targeted in the aforementioned pathways.
\end{abstract}

Keywords COVID-19 $\cdot$ Neuropathogenesis $\cdot \mathrm{NF}-\mathrm{kB} \cdot \mathrm{Nrf2} \cdot$ Oxidative stress

\section{Introduction}

In December 2019, several cases presenting pneumonia came up in Wuhan, China. The samples were taken from the lower respiratory tract and the organism was identified as a novel coronavirus [1]. After the analysis of the genome of the causative organism, it was identified to be SARS-CoV-2 (severe acute respiratory syndrome coronavirus-2) [2, 3]. COVID-19 received the status of a pandemic on March 11, 2020, by WHO [4]. Since its first reported case in Wuhan, China in December 2019, the disease has come a long way, with the number of cases and the number of deaths surging daily. The primary manifestations of COVID-19 are known to be respiratory, but several pieces of evidence suggest the involvement of the nervous system too, which results in a range of neurological complications $[5,6]$. Several studies have established

Ranjana Bhandari

akb10in@yahoo.co.uk

Anurag Kuhad

anurag_pu@yahoo.com; anurag.kuhad@pu.ac.in

1 Pharmacology Research Laboratory, University Institute of Pharmaceutical Sciences, UGC-Centre of Advanced Study, Panjab University, Chandigarh 160 014, India the incidence of neurological complications, both related to CNS (central nervous system) and PNS (peripheral nervous system) that have been quoted further in the article. These can be seen in the form of impaired consciousness, headache, dizziness, paraesthesia, encephalitis, infectious toxic encephalopathy, acute cerebrovascular diseases, and many others. These are more prevalent in patients in severe stages of infection $[7,8]$. Cognitive dysfunction and memory loss have been reported in very few studies. A retrospective study on 50 hospitalized patients in Chicago revealed $24 \%$ of patients with short-term memory loss and 13 patients presented cognitive impairment [9]. Another study in the UK also reported COVID-19 patients with altered mental status having neurocognitive dysfunction such as new-onset psychosis, neurocognitive (dementia-like) syndrome, and an affective disorder apart from other neurological complications such as ischaemic stroke, intracerebral hemorrhage, CNS vasculitis, encephalopathy, and encephalitis [10]. Potential mechanisms of neuroinvasion have also been proposed, though there is still lesser clarity on them. The entry of the virus into the brain can be mediated by endothelial cells of BBB (blood-brain barrier) or epithelial cells of the blood-CSF barrier or through the inflammatory cells produced in the cytokine storm during COVID-19 infection. Retrograde axonal transport through the olfactory, enteric nervous system, and the respiratory 
system could be the other possible routes of brain infection. The increasing evidence shows that it might be possible for the SARS-Cov2 virus to gain access to the cardiorespiratory center of the medulla oblongata in the brain through a synapse-connected route after invading peripheral nerve terminals such as mechanoreceptors and chemoreceptors present in the lungs and lower respiratory airways.

Blood circulation is another route that facilitates the entry of the viral particles and the inflammatory mediators into the brain [11]. Another mechanism is attributed to be injury through hypoxia that causes brain swelling, cerebral vasodilation, headache due to ischemia, and obstruction of cerebral blood flow which may worsen if hypoxia goes untreated and may result in coma or stroke [7]. The detailed mechanisms, with a specific focus on NF- $\mathrm{KB}$ and Nrf2 pathway, have been discussed in this review.

The release of a large number of cytokines in SARS-CoV-2 infection has now been well documented in various studies. In a study in Wuhan, higher levels of IL-2, IL-10, IL-7, TNF- $\alpha$, and other inflammatory markers were found in the ICU patients than the non-ICU patients admitted for COVID-19 [12]. Another similar study on 452 patients, out of which 286 were severe cases, elevated levels of inflammatory cytokines, and biomarkers related to infection were found in severely infected patients. T-cells, monocytes, basophils, and eosinophils had a lower count [13]. Increased levels of C-reactive protein, D-dimer, ferritin, IL-6, IL-10, IL-2R, TNF- $\alpha$, and markedly reduced levels of T-lymphocytes, CD8 + T cells, and CD $4+\mathrm{T}$ cells were found in the severe cases of COVID-19 in another study [14]. The pathway for this hyper inflammation has been demonstrated to be through NF-KB by some studies. In a study on 48 Korean subjects, the genes that are involved in the NF-KB signaling pathway were found to be upregulated, along with increased levels of cytokines and inflammatory markers, showcasing the involvement of this pathway in the hyperinflammatory response in patients with COVID-19 [15]. NF- $\mathrm{KB}$ (nuclear factor $\mathrm{KB}$ ) is a family consisting of inducible transcription factors that regulate the genes involved in immune and inflammatory responses. These normally exist in the cytoplasm in a sequestered form by inhibitory proteins that include the I $\mathrm{kB}$ family and some other related proteins. The most prominent member of the IKB family is I $\mathrm{I} B \alpha$. Phosphorylation of I $k B$ during inflammation leads to the release of NF-KB. Thus, NF- $\mathrm{KB}$ activation is a hallmark of inflammatory diseases [16].

Nrf2 (nuclear factor erythroid 2 related factor-2) is a transcription factor that forms the genes coding for various enzymes that protect the cells from oxidative or electrophilic stress. It also transcriptionally represses inflammatory genes that regulate the inflammatory response. Normally, Nrf2 exists in bound form in the cytoplasm with its inhibitor, Keap1. When the cell is under stress, electrophile or ROS (reactive oxygen species) generation leads to dissociation of Nrf2-
Keap1 complex and Nrf2 migrates into the nucleus to stimulate the transcription of a multitude of genes that are involved in redox homeostasis and anti-oxidant response [17]. Biopsies in COVID-19 patients have revealed that genes associated with Nrf2 anti-oxidant response were suppressed in these patients. Also, in vitro experiments showcased that the Nrf2 inducible proteins expression was also downregulated that tells the suppression of this pathway in COVID-19 patients [18]. A study on Nrf2 activator showed that it downregulated 36 genes that encode cytokines resulting in a decrease in the cytokine storm in COVID-19 [19].

All the above studies point to the involvement of Nrf2 and NF-KB in the pathogenesis of COVID-19. Since one of the mechanisms of neurological complications is through immune injury by the cytokines, the involvement of these signaling pathways in these complications can be well attributed. A study on transgenic mice also revealed that when the $\mathrm{Nrf} 2$ pathway was activated, it suppressed oxidative stress and improved the cognitive function of mice. When the pathway was blocked, it resulted in oxidative injury and a decrease in the viability of neurons [20]. As this pathway is reported to be downregulated in COVID-19 patients, this could be one of the possible causes of cognitive decline. The detailed signaling of both these pathways as well as their involvement in the neurological invasion of SARS-CoV-2 has been discussed. The potential mechanisms of crosstalk between these two pathways have also been viewed upon. Immuno-modulators both synthetic and natural which can modulate the Nrf2-Keap1 pathway or can inhibit NF-KB hence, affecting crosstalk are promising candidates in catering to the pathologies targeted in the aforementioned pathways. The compilation of promising candidates which can be explored as a therapeutic against COVID-19 has also been discussed.

\section{Structure of SARS-CoV-2}

SARS-CoV-2 is a beta-coronavirus that has single-stranded positive-sense RNA. It belongs to the family Coronaviridae and has a diameter between 80 and $220 \mathrm{~nm}$ [1]. SARS-CoV-2 has four main structural proteins - small envelopes (E) glycoprotein, spike (S) glycoprotein, nucleocapsid (N) protein, membrane (M) glycoprotein, and some other accessory proteins. $\mathrm{M}$ glycoprotein is the most abundant that spans the membrane 3 times. The $\mathrm{N}$ protein binds to nucleic acid material and plays a role in the viral replication cycle and is also involved in the cellular response elicited by the host cells to the infection. The S-glycoprotein weighs about $150 \mathrm{kDa}$. It is a transmembrane protein that is present in the form of spikes on the viral outer surface. This is only responsible for binding to the host cell receptors, ACE2. Some accessory proteins like HE (hemagglutinin esterase), $4 \mathrm{a} / \mathrm{b}$, and $3 \mathrm{a} / \mathrm{b}$ protein are involved in virus replication and maintenance of the genome 
$[21,22]$. The spike glycoprotein is responsible for binding to the host cell receptors, ACE2 as well as to the CD147 receptor (also called basigin or EMMPRIN). CD147 is a transmembrane glycoprotein that belongs to the immunoglobulin superfamily and shows increased expression in the case of tumors or inflammatory processes [23]. It was recently demonstrated in a study that SARS-CoV-2 binds to CD147 receptors, apart from ACE2. A direct interaction was reported between the spike glycoprotein and CD147 by the finding that blocking of this receptor inhibited the viral replication [24]. To date, there has been an entire focus on the entry of SARS-COV-2 into the host cell via ACE2 receptors which are expressed at very low protein levels in the olfactory as well as respiratory epithelial cells. Hence, it was observed that there is a possibility that cofactors are required to facilitate virus-host cell interactions in cells with low ACE2 expression. Moreover, ACE2 is not present in most neurons despite increasing reports of neurological symptoms being common in COVID-19 patients. Hence, it supports the hypothesis that ACE2 is not the sole entry point for SARS-COV-2. Scientific literature has indicated that the SARS-CoV-2 spike protein can also bind to the b1b2 domain of the neuropilin-1 receptor (NRP-1). NRP1 receptor is present in the human respiratory and olfactory epithelium and it was observed that olfactory epithelium of patients infected with COVID-19 had enhanced expression of NRP1. NRP1 significantly potentiated infectivity of SARS$\mathrm{CoV}-2$ virus as observed from the pathological analysis of olfactory epithelium obtained from autopsy reports of COVID-19 patients[25, 26]. Another research report by Moutal et al. [27] reinforced the involvement of NRP1 for entry of SARS-COV-2 into the host cell. Since, both the spike protein of SARS-COV-2 and vascular endothelial growth factor-A (VEGF-A) bind to NRP-1, they tested weather
VEGF-A/NRP-1 signaling was blocked by spike protein. It was observed that VEGF-A-triggered sensory neuron firing was blocked by spike protein as well as NRP-1 inhibitor substantiating the involvement of NRP1 in facilitating entry and infectivity of COVID-19 Fig. 1.

\section{Symptoms of SARS-CoV-2 Infection}

COVID-19 primarily spreads through the respiratory droplets from an infected person. The primary manifestations of COVID-19 include fever, fatigue, and dry cough. Out of 138 patients in a study, $26.1 \%$ of patients progressed to complications like ARDS (acute respiratory distress syndrome), arrhythmia, and shock. Most of these patients were old and had co-morbidities existing already [28]. Another study showed fever, cough, and shortness of breath among the major symptoms while a lesser percentage had muscle ache, confusion, sore throat, headache, rhinorrhea, diarrhea, chest pain, and nausea-vomiting. Seventeen percent of patients developed ARDS [29].

Apart from these respiratory symptoms, several studies have shown that patients exhibit neurological symptoms as well. A systematic review presented the main CNS complications to be an ischaemic stroke, acute myelitis, encephalomyelitis, and intracranial hemorrhage. The PNS complications were mainly GBS (Guillain-Barre syndrome) and Bell's palsy, while rhabdomyolysis was the main skeletal muscle manifestation [30]. In a UK-wide surveillance study on 153 patients, $62 \%$ had cerebrovascular events (ischaemic stroke, $74 \%$; cerebral vasculitis, $1 \%$; intracerebral hemorrhage, $12 \%$; other cerebrovascular events, $13 \%$ ); $31 \%$ showed altered mental status (encephalitis, 18\%; unspecified

Fig. 1 Structure of SARS-CoV-2

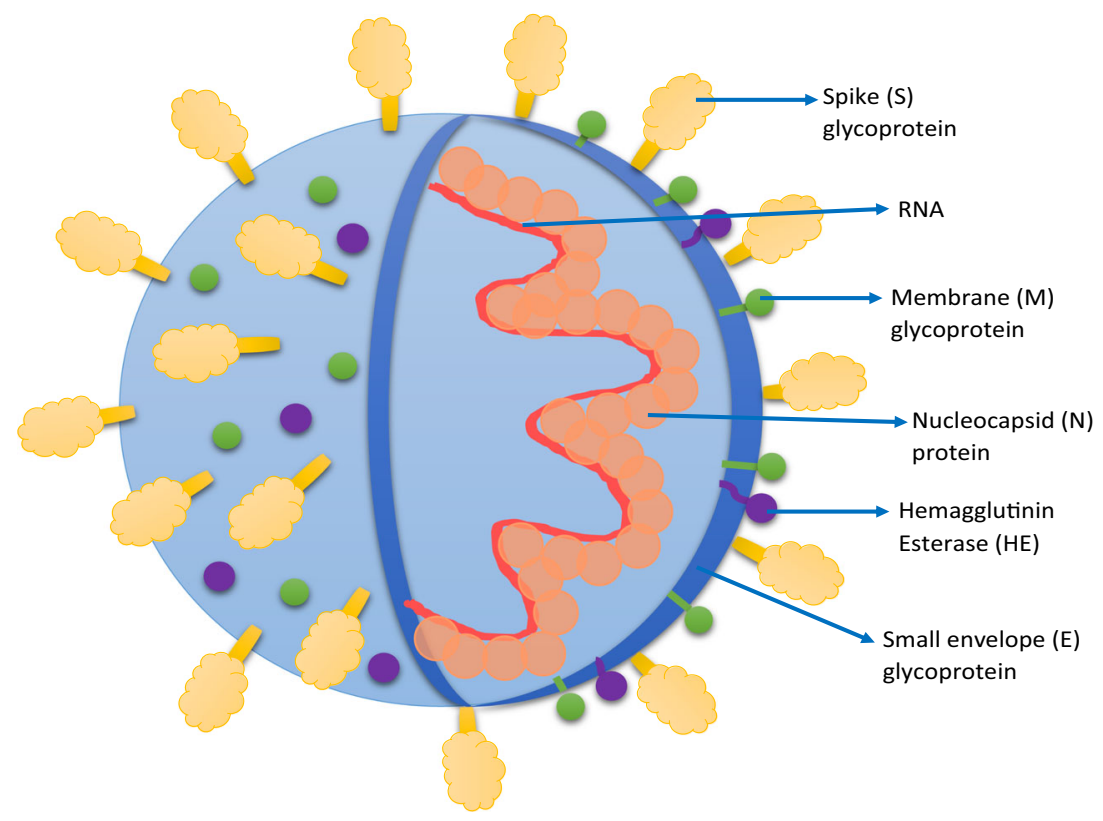


encephalopathy, 23\%; neuropsychiatric disorders, $59 \%$ including psychosis, $43 \%$; neurocognitive disorder, $26 \%$ and other psychiatric disorders, $36 \%$ ); $5 \%$ showed peripheral disorders (GBS, $67 \%$; other peripheral disorders, $23 \%$ ); and $2 \%$ had other neurological disorders [10].

In another study on 214 subjects, $36.4 \%$ had neurological findings out of which $24.8 \%$ were CNS related and $8.9 \%$ were PNS-related. The CNS-related were dizziness in $16.8 \%$, impaired consciousness in $7.5 \%$, headache in $13.1 \%$, acute cerebrovascular diseases in $2.5 \%$, epilepsy in $0.5 \%$, ataxia in $0.5 \%$ of the patients. The PNS-related findings were hypogeusia in $5.6 \%$, hyposmia in $5.1 \%$, and neuralgia in $2.3 \%$ of the patients [8]. The patients in France also showed neurological features with $84 \%$ of 58 patients showing neurological complications. Fifteen out of 45 patients showed cognitive impairment following discharge from ICU, mainly characterized by disorientation, inattention, and poor response to commands [31]. In another case study of four critical COVID-19 patients admitted in ICU, cognitive impairment was identified after discharge, mainly manifesting as a frontal syndrome and memory deficit. But this was soon remitted after immunoglobulin therapy for 5 days [32]. In another study on 71 hospitalized COVID-19 patients diagnosed with delirium in course of their hospitalization, $42 \%$ of them had lower cognitive scores in a telephonic interview 4 weeks after discharge [33].

MRI brain findings in 126 patients also showed acute or subacute infarcts in 32 cases, microhemorrhages in 14 cases, leukoencephalopathy in 17 cases, hypoxic ischemic encephalopathy in 1 case, leptomeningeal enhancement in 14 cases among the other findings [34]. Out of 59 patients in another study, $33.9 \%$ of them reported taste of olfactory disorders. Dysgeusia was reported in $8.5 \%$, ageusia in $1.7 \%$, and hyposmia in $5.1 \%$ of the patients. Mixed taste and olfactory disorders were also reported in $18.6 \%$ of the patients including dysgeusia and hyposmia in 3.4\%; dysgeusia and anosmia in $3.4 \%$; ageusia and hyposmia in $3.4 \%$; ageusia and anosmia in $8.5 \%$ of the patients [35].

\section{Epidemiology}

With the appearance of the first case in Wuhan in December 2019, SARS-CoV-2 has spread to all the regions with many countries being severely affected. According to WHO, 37 million cases and over 1 million deaths were reported globally as of October 11 with 67,000 new deaths and 7 million new cases added to the list by November 24, 2020, making the number to 57.8 million reported cases and over 1.3 million reported deaths globally [36]. According to the Weekly Epidemiological Update by WHO issued on December 22, 2020, 75 million cases and 1.6 million deaths were reported since the pandemic start on December 20. USA, Brazil, Turkey, Russian Federation, and India were the five countries that reported the highest case numbers in which the USA, Brazil, and Russian Federation experienced a 14\%, $8 \%$, and less than $1 \%$ increase in cases respectively while Turkey and India experienced $11 \%$ and $18 \%$ decrease respectively in the case numbers [37]. As of February 13, 2021, 107,838,255 confirmed cases and 2,373,398 deaths were reported globally. The Americas region reported the highest confirmed cases while Western Pacific Region had the lowest number. Country-wise, the USA, India, and Brazil are the three leading countries in terms of confirmed cases [38]. Figure 2 shows the situation in numbers as of February 13, 2021.

Some studies have shown a higher prevalence of COVID-19 infection in men than in women. A meta-analysis of 57 studies that included 221,195 participants in total found the pooled prevalence in men to be 55.00 that indicated men were more susceptible to the infection. This analysis attributed this difference due to the higher incidence of smoking and alcohol consumption among men [39]. Another case series analysis on 43 patients revealed that the deceased rate is more in men as compared to women. Out of 37 patients who died due to the infection, $70.3 \%$ were males while $29.7 \%$ were females. The number of deceased men was 2.4 times that of deceased women [40]. This could be attributed to the fact that the $\mathrm{X}$ chromosome displays a higher
Fig. 2 Percentage of confirmed COVID-19 cases in WHO Regions as of February 13, 2020

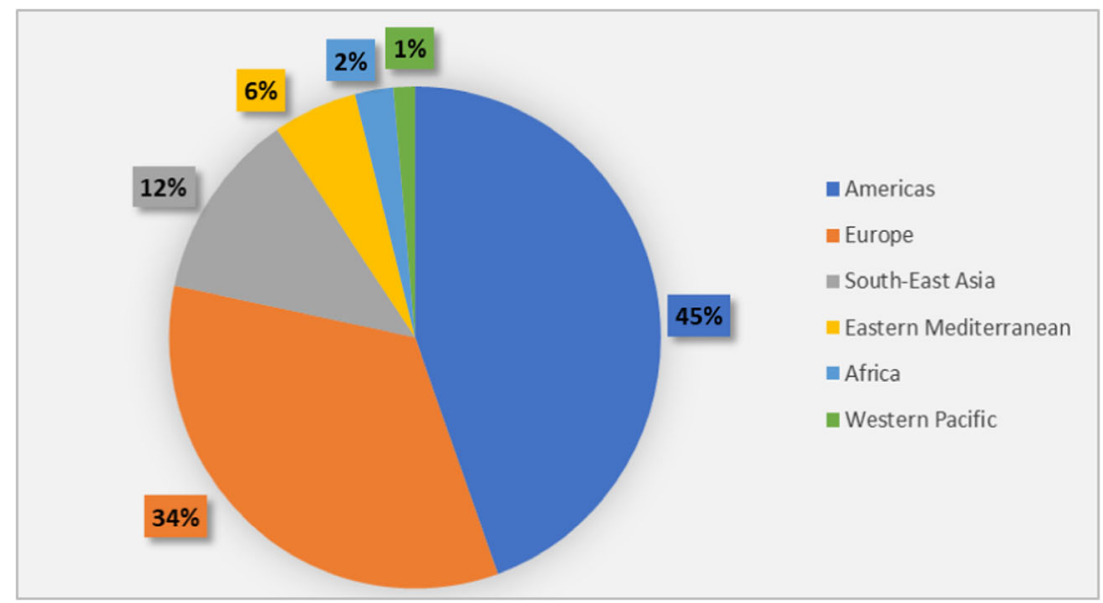


number of immune-related genes that make the innate and adaptive immune responses stronger in women than in men [41]. The transmission of the virus is from human-to-human, mainly via respiratory droplets through sneezing, coughing, or direct contact with the infected person [42]. The droplets can also infect the surfaces and transmission may also occur by touching these surfaces and then touching your mouth or nose with the same hands. The incubation period generally varies between 2 and 14 days [43]. The basic reproduction number, R0, was also estimated for SARS-CoV-2 in several studies. A range of 1.4-6.49 was estimated initially. After this, an analysis multitude of studies estimated the average R0 value to be 3.28 and a median value of 2.79. Hence, $2-3$ was found to be a reliable range that points to the transmission from human-to-human. Super-spreaders have the potential to infect more than 100 people [42].

\section{Pathogenesis}

Several studies have claimed that the ACE2 receptor is the one through which SARS-CoV-2 gains entry into the host cell [44, 45]. ACE2 has been found to show its expression on the alveolar epithelial cells of the lungs and in enterocytes in the small intestine. ACE2 receptors are expressed in both Types I and Type II alveolar cells. They are also present in the oral and nasal mucosa and nasopharynx. In the brain, ACE2 expression was found in endothelium and vascular smooth muscle cells [46]. ACE2 expression in the brain is lower than in other organs. The outer surface of SARS-CoV-2 houses the transmembrane spike(S) glycoproteins that are believed to mediate the entry of the virus into the host cell. S1 and S2 are the two subunits of S-glycoprotein. The S1 subunit has the RBD (receptor-binding domain) that binds directly to PD (peptidase domain) of the ACE2 receptors. The S2 subunit plays its role in membrane fusion of viral and host cell membranes [44]. After the binding of SARS-CoV-2 to ACE2 receptors, there occurs proteolytic cleavage by TMPRSS2 protease. In this, first of all, priming occurs at $\mathrm{S} 1 / \mathrm{S} 2$ cleavage site that stabilizes the $\mathrm{S} 2$ subunit. Then, a second cleavage occurs that activates S-glycoprotein by conformational changes, and viral and host cell membranes fuse. After this, the viral contents are released into the host cells which starts the viral replication. The $\mathrm{N}$ protein present in the virus is responsible for binding to the new genomic RNA and integration to the endoplasmic reticulum (ER) is facilitated by the M protein. These nucleocapsids are enclosed in the membrane of ER and transported to the lumen and then to the cell membrane by the Golgi vesicles. Via exocytosis, these viral particles reach the extracellular space and invade the surrounding epithelial cells. This is the stage of community spread of the virus [47]. Figure 3 represents the pathogenesis of COVID-19.

The respiratory pathogenesis starts with the binding of SARS-CoV-2 to ACE2 receptors in the nasal epithelium where it undergoes propagation and local replication. This generates a limited immune response and highly infectious individuals, although the viral load is low. In the next stage, the virus migrates to the upper respiratory tract with the appearance of clinical symptoms like fever, dry cough, and malaise. The infected cells generate a greater immune response by the release of CXCL-10 (C-X-C motif chemokine ligand 10) and interferons- $\beta$ and $\lambda$. From here, in about one-fifth of the patients, the infection progresses to the lower respiratory tract. Pulmonary infiltrates are developed and a range of cytokines and inflammatory markers are released including interleukins$1,6,8120,12$, TNF- $\alpha$, MCP-1 (monocyte chemoattractant protein) among others. These chemokines attract the neutrophils, CD8 and CD4 T cells, and their sequestration in the lung tissue begins that manifests as lung injury. Both Type I and Type II alveolar cells are infected, severe scarring, and fibrosis occur leading to diffuse alveolar damage that finally manifests as ARDS (acute respiratory distress syndrome) [47, 48].

Various routes of brain invasion of SARS-CoV-2 have also been proposed. The viral particles or the inflammatory mediators released can directly reach the brain by disrupting the tight junctions of the blood-brain barrier. Also, the sluggish blood circulation may facilitate spike protein binding with ACE2 receptors on the capillary epithelium [11]. The neuronal pathway could be by retrograde axonal transport through the respiratory, olfactory, and enteric nervous systems. From the nasal cells, the virus can reach directly to the brain via the olfactory bulbs and travel to the thalamus and brainstem causing neuroinflammation and demyelinating reactions. Cardiorespiratory function occurs in parts of the brainstem. Therefore, front-line workers may be treating respiratory effects of COVID-19 with methods such as ventilators, which may be ineffective if the respiratory areas are affected with COVID-19 [49, 50]. Invasion of peripheral nerve terminals in the respiratory system may also provide the virus access to the CNS through the synapse. Similarly, the sympathetic afferent neurons in the ENS (enteric nervous system) may also be an entry point of the virus to the CNS when it infects the gastrointestinal tract [11]. Another mechanism could be a hypoxic injury that leads to anaerobic metabolism in brain cell mitochondria which causes accumulation of acidic compounds that can cause brain swelling, cerebral vasodilation, ischaemic stroke, obstruction of cerebral blood flow, etc. Immune injury through local cytokine production can be another mechanism as it increases the permeability of the blood-brain barrier [7]. Patients with the cerebrovascular disease also showed a higher inflammatory response in a study, which points to the possibility that hyper inflammation leads to a high coagulation state that increases incidences of stroke [51]. Binding to ACE2 receptors also leads to increased blood pressure that increases the chances of cerebral hemorrhage [7]. Mechanisms involved in cognitive decline are not yet fully clear but can be attributed to direct infection of the nervous system, the systemic hyper 
Fig. 3 Pathophysiology of COVID-19

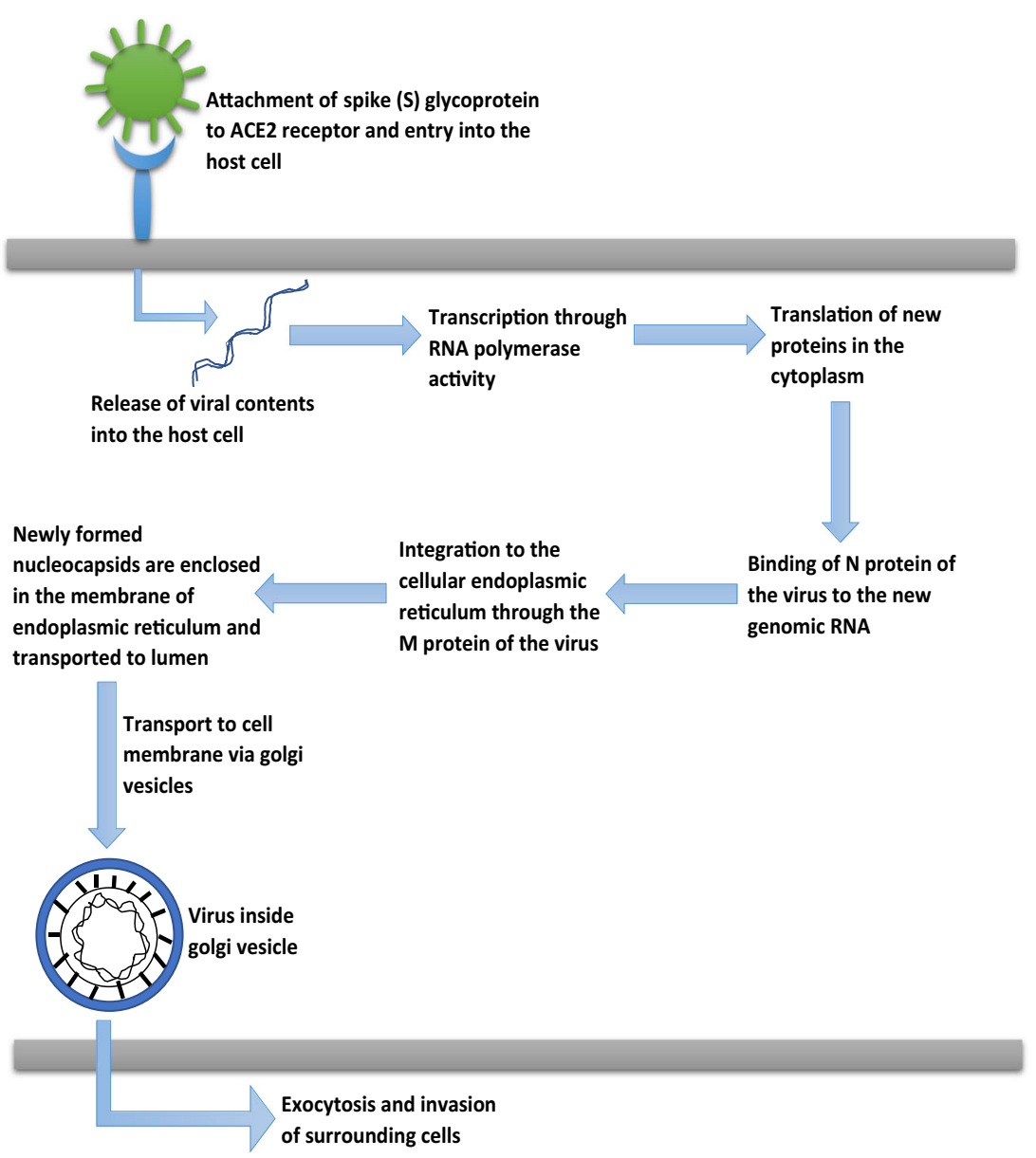

inflammatory response, acute respiratory distress syndrome (ARDS), invasive ventilation, and sedation or side effects of the drugs used for COVID-19 [52]. Figure 4 depicts the various possible routes of neuro-invasion of SARS-CoV-2.

\section{Neurological Complications and Their Possible Mechanisms}

\section{Headache}

Several studies have reported headache as to be the common initial symptom in COVID-19 patients [8, 29]. The pain was mostly reported in the tempo-parietal region or anteriorly towards the forehead. The first suggested mechanism was the direct invasion of the virus on the trigeminal nerve endings present in the nasal cavity. Secondly, trigeminovascular activation may occur via ACE2 receptors present on the endothelial cells that may also lead to a headache. Thirdly, the cytokines and pro-inflammatory mediators released during COVID-19 may also trigger perivascular trigeminal nerve endings that may also be the cause of headache [53].

\section{Cerebrovascular Events}

Elevated levels of Interleukins (IL-6, IL-7), C-reactive protein (CRP), and other inflammatory markers due to the hyperinflammatory response in COVID-19 make the already existing atherosclerotic plaque more rupture susceptible [54]. Another mechanism can be the depletion of ACE2 by the virus as it binds to these receptors that may cause an imbalance in RAS (renin-angiotensin system) and result in ischaemic events [55]. This ACE2 downregulation may also cause vasoconstriction which leads to cerebral autoregulation dysfunction. This manifests as an increase in blood pressure and can cause rupturing of arteries resulting in hemorrhage [56].

\section{Demyelinating Diseases}

A systematic review analyzed that acute encephalomyelitis was reported in four patients while acute myelitis was reported in five patients [57]. The proposed mechanism was myelitis was secondary immunogenic overreaction after COVID-19 infection. Cytokines released in COVID-19 might explain the involvement of the spinal cord in this disease [58]. 
Fig. 4 Various proposed routes of neuro-invasion of SARS-CoV-2 after it entered into the host cells. 1- Migration of viral particles directly into the brain from the nasal passage via olfactory bulb, 2hypoxia due to lung injury causes anaerobic respiration in the brain cells mitochondria leading to accumulation of acidic compounds that causes brain swelling, ischemia, and obstruction in cerebral blood flow, 3-cytokines and inflammatory markers released during the cytokine storm travel to the blood-brain barrier and increase its permeability, thus infiltrating into the brain, 4- virus infects the gastrointestinal tract and travels to the CNS via sympathetic afferent neurons in the enteric nervous system

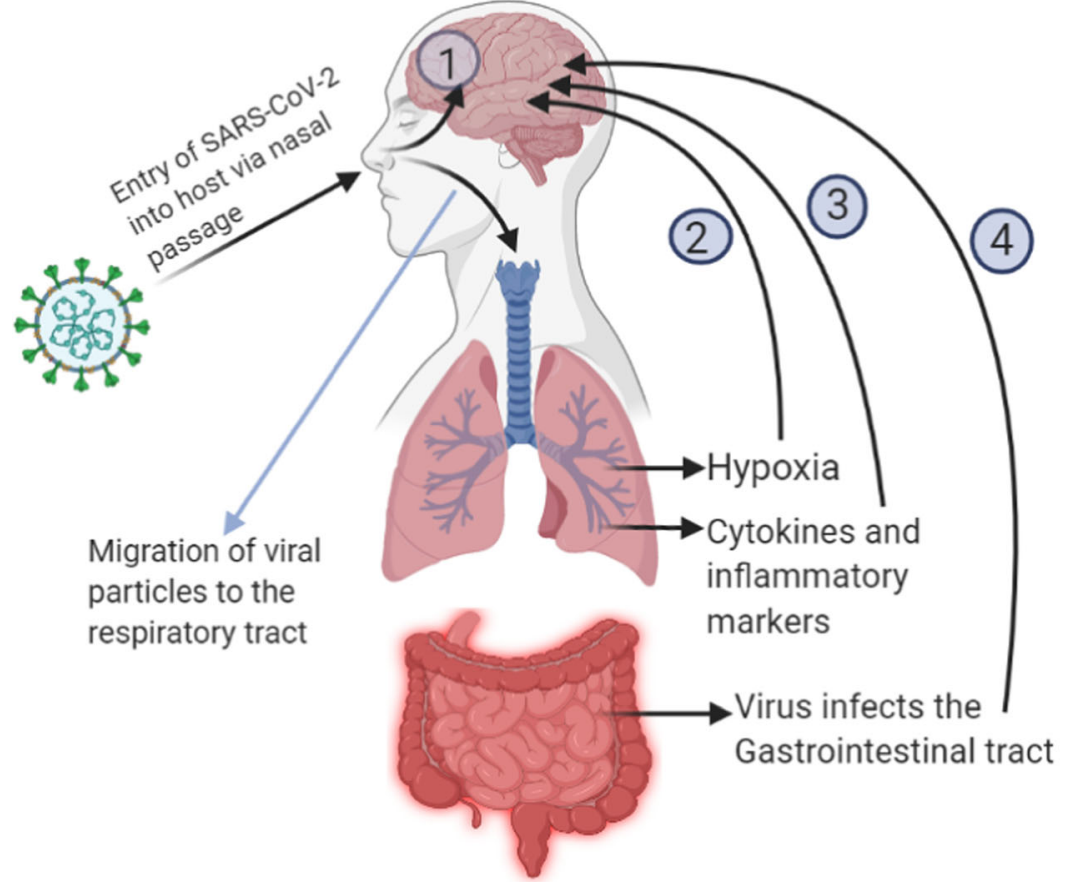

Created in BioRender.com bio

\section{Encephalitis}

SARS-CoV-2 RNA was detected in the cerebrospinal fluid of a patient diagnosed with encephalitis [59]. Two potential mechanisms are suggested for encephalitis, the first one being through the olfactory and trigeminal nerve endings that results in central infiltration of SARS-CoV-2. Another reason could be an invasion by pro-inflammatory cytokines that increase the permeability of the blood-brain barrier and reach the central nervous system [57].

\section{Encephalopathy}

Confusion to delirium progressing to stupor and coma can be the manifestations of altered sensorium in COVID-19 patients in severe stages [60]. Diffuse white matter T2 hyperintensity and restricted diffusion were reported in some COVID-19 patients who were critically ill. Although the exact cause is still not known, it is proposed to be due to delayed posthypoxic leukoencephalopathy. Leukoencephalopathy is proposed to occur after about 10-14 days following hypoxia that can also lead to oligodendroglial cell death and demyelination. Other etiologies could be the direct cerebral infection, postinfectious demyelination, and sepsis-associated encephalopathy [61]. Acute necrotizing encephalopathy (ANE) reported is proposed to be due to the cytokine storm associated with SARS-CoV-2. An intense surge in the levels of proinflammatory cytokines causes damage to the blood-brain barrier by increasing its permeability that can cause edema and necrosis [62].

\section{Seizures}

The viral infection in the CNS and the subsequent activation of inflammatory pathways in the brain lowers the seizure threshold and can facilitate epileptogenesis [63]. Local cortical irritation due to the accumulation of various inflammatory markers in the brain can also lead to seizures. Viral encephalitis as well as direct viral invasion of CNS can be the other causes of seizures [57, 64]. Critically ill patients presenting with electrolyte or metabolic imbalances, hypoxia, and inflammatory processes can also experience seizures or an abnormal EEG [65].

\section{Cognitive Decline and Memory Loss}

As discussed earlier in the article, few studies have reported short-term memory loss and neurocognitive disorder following COVID-19 infection. Majorly proposed mechanism of neurodegeneration is chronic systemic inflammation [52]. A study established the correlation of inflammatory factors and levels of C-reactive protein (CRP) in the patients that exhibited cognitive dysfunction. This study was done around 2-3 weeks after infection; hence, the assessment was short term. Further long-term studies are still required to establish proper evidence of inflammation-induced cognitive decline. It also 
demonstrated a significant correlation between changes in attention and CRP levels when the patients were admitted for COVID-19 [66].

\section{Guillain-Barre Syndrome}

Molecular mimicry is the likely mechanism of GBS in which the pathogen has epitopes similar to peripheral nerve components. The host immune system produces antibodies to fight against the viral infection. These cross-react and bind to peripheral nerves that results in neuronal dysfunction [57, 67].

\section{Loss of Smell and Taste}

These are some of the first manifestations of COVID-19. The most proposed mechanism for these is that SARS-CoV-2 binds to ACE2 receptors in the olfactory epithelium and enters the neuronal cells spreading to the olfactory bulb via the olfactory nerve that leads to loss of sense of smell [60]. The frequency of loss of smell is high. Out of those reporting chemosensory impairment, 65\% had a subsequent positive PCR for Covid-19 [68].

\section{Neuromuscular Junction and Skeletal Muscle Abnormalities}

Myalgia, general muscle pain, and fatigue are common symptoms of COVID-19. Muscle injury was noted, especially more in severe cases of COVID-19 [8]. Majorly proposed risk factors are acute respiratory distress syndrome (ARDS), sepsis, and systemic inflammatory response. As the ACE2 receptor is also present on muscle cells, the virus can directly invade the cells and cause muscle injury. The hyperinflammatory cytokine storm could also lead to immune-mediated muscle damage $[69,70]$.

\section{Neurological Complications and Their Pathology Associated with NF-KB and Nrf2 Pathways}

\section{NF-KB Pathway and COVID-19}

The NF-KB (nuclear factor $\mathrm{k}$-light-chain-enhancer of activated $\mathrm{B}$ cells) transcription factor family is a pleiotropic regulator of many cellular signaling pathways which provide mechanisms for stimuli that link to inflammation. It influences the growth of axons and dendrites originating right from the earliest stages of neuron establishment [71]. A lipopolysaccharide receptor complex is formed by toll-like receptors and the adaptor proteins present in the extracellular matrix. The signal pathway leads to activation of NF- $\mathrm{KB}$. The blood-brain barrier prevents the entrance of immunogenic cells into the central nervous system [72]. The stimulated cells will be regulated by not only the canonical but also non-canonical NF- $\mathrm{kB}$ pathways. Besides neurons, NF- $\mathrm{kB}$ transcription factors are abundant in glial cells and cerebral blood vessels, and the diverse functions of NF- $\mathrm{KB}$ also regulate the inflammatory reaction around the neuronal environment. NF- $\mathrm{KB}$ transcription factors are abundant in the brain and exhibit diverse functions [73]. The pathogenesis of COVID-19 is similar to earlier discovered viral disorders namely cytomegalovirus, MERS, and varicella. Similarly, COVID-19 can cause activation of the NF- $\mathrm{KB}$ pathway which ultimately may lead to stroke or neuropathy associated with thromboembolism in the brain. The heightened immune response specially, the cytokine storm is characterized by an elevation in IL-6, IL-10, IFN- $\gamma$, and TNF- $\alpha$ in the granulocyte colony-stimulating factor [74]. The genetic induction of innate and adaptive immunogenic cells is influenced by NF-KB. Deregulated activation leads to activated T-cells in association with autoimmune inflammation and inflammasome release [75]. In a preclinical study, $\mathrm{NF}-\mathrm{KB}$ influenced the regulation of various proinflammatory mediating chemicals. When inhibitors of NF-KB like parthenolide were administered, a reduced infection was seen. The NF- $\mathrm{KB}$ transcription is unmasked by the degradation of I $\mathrm{B}$ which is phosphorylated by protein kinases activated by mitogens [76]. The upregulated proinflammatory genes result in excessive cytokine and reactive oxygen species which cause cerebellar damage and neuropathogenic dysregulation associated with neurotransmitters [77].

\section{Nrf-2 and COVID-19}

Nrf2 belongs to the basic leucine transcription factor and influences oxidative stress by expressing antioxidant genes [78]. $\mathrm{Nrf2}$ remains situated in the cytoplasm wherein it binds with keap1, which is a known inhibitor of Nrf2. When reactive oxygen species emerge, the Keap1-Nrf2 complex gets dissociated and as a result, Nrf2 migrates towards the nucleus leading to stimulation of target genes eliciting an antioxidant action whose activation enforces protection from inflammation [17]. Upregulation in expressing Phase 1 and 2 drug-metabolizing enzymes in addition to the mitochondrial pathways is also a characteristic of this pathway. The upregulated target genes include glutathione S-transferase, catalase, heme oxygenase 1, and superoxide dismutase. These protect neuron function from oxidative degradation. All primary factors including oxidative degradation, inflammatory upregulation, and dysfunctional mitochondria contribute to aging of brain which exposes patients at a risk of neurodegenerative diseases. Nrf2 can prove to be beneficial in case of COVID-19 infections due to it's attractive efficacy against such pathologies [79]. To eradicate stress induced by oxidative species, Nrf2 is released, stabilized, and translocated. Nrf2 acts as an on-off switch and produces endogenous antioxidative relief. Several kinases like phosphoinositol3 kinase, protein kinases, and pancreas enriched kinase also act as regulators of Nrf2 activity [80]. Mitogen-activated protein 
kinases are enzymes that contain protein kinases regulated extracellularly. They catalyze the phosphorylated reactions on the amino acid serine, threonine residues which reside right next to the proline amino acid. The mitogen-activated protein kinase pathway works in response to oxidative stress and has been implied in the induction of the Nrf2 pathway [81]. The signals are mediated by the extracellular regulated kinase and mitogen activated kinases which culminate in upregulation of glutamate cysteine ligase modulatory subunit gene, influencing nuclear translocation of Nrf2. While Nrf2 and Keap1 are not directly targeted, the mitogen-activated kinases are directly involved in the translocation of Nrf2 into the nucleus [82].

\section{Crosstalk Between NF-kB and Nrf2 Pathways}

After the virus replicates inside the host, the innate immunogenic response causes activation of many inflammatory mediators namely macrophages and dendritic cells to fight against cytokines and reactive oxygen species. The reactive oxygen species and inflammatory cytokines damage erythrocytes releasing heme and free ion. Respiratory burst generates superoxide radicals and hydrogen peroxide which ultimately, cause oxidative stress. The cytokine storm is a consequence of the upregulates cytokine expression through the NF-KB pathway. This storm is responsible for severe damage to the tissue [83].

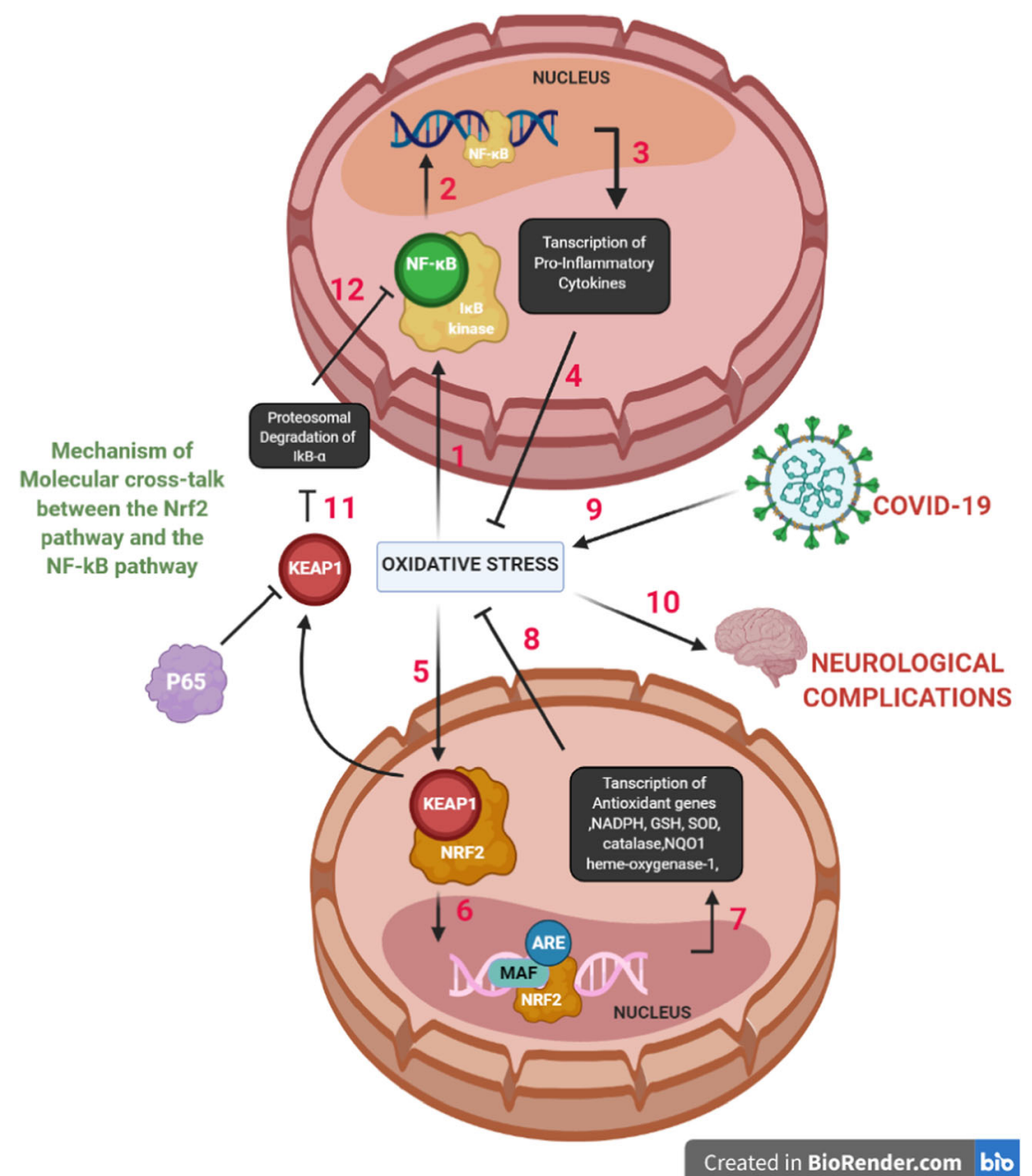

Fig. 5 Crosstalk between NF-kB and Nrf2 pathways mediated by COVID-19 infection leading to neurological complications. (1) Enhanced oxidative stress/cytokine storm leads to activation of IK $\beta$ kinase, which causes phosphorylation of IkB- $\alpha$, an NF-kB inhibitor, and results in proteasomal degradation of IkB- $\alpha$. (2) NF-kB binds to its region, p65 subunit after migrating into the nucleus. p65 is an inhibitor of KEAP1. (3) This results in transcription of pro-inflammatory cytokines and other genes such as TNF- $\alpha$, Il- $\beta$, Il-6, iNOS, COX-2. (4) The NF-kB pathway and its contributing pro-inflammatory cytokines aggravate the oxidative state. (5) Oxidative stress leads to the activation of the Nrf2 signaling pathway resulting in dissociation of Nrf2 from its inhibitor Keap1. (6) It then causes translocation of Nrf2 to the nucleus and associates with Maf protein and antioxidant response element (ARE). (7) Transcription of antioxidant genes and phase II enzymes such as NADPH, GSH, SOD, catalase, heme-oxygenase-1, and NQO1 occurs which inhibits ROS. (8) Overall, the genetic interventions and consequent transcription show positive implications of $\mathrm{Nrf} 2$ pathway in reducing oxidative stress. (9) COVID-19 infection induces oxidative stress. (10) Oxidative stress drives neurological complications. (11) Free Keap1 prevents degradation of IkB- $\alpha$. (12) Inhibition of the NF-kB pathway 
In a study that induced scratch injury in astrocytes, it was found that this injury caused upregulation of NF- $\mathrm{KB}$ activity that resulted in overexpression of IL- 6 , IL- $1 \beta$, TNF- $\alpha$, and MMP9 (matrix metallopeptidase 9-gelatinase that aggravates inflammation process). This overexpression was found to be more aggravated in Nrf2 knockout astrocytes than the wildtype resulting in more astrocyte death [84]. In another experiment, Nrf2-deficient mice showed greater pro-inflammatory gene expression on TNF- $\alpha$ stimulation. NF- $\mathrm{KB}$ activation after LPS (lipopolysaccharide) activation was also found to be high in the lungs, MEFs (mouse embryonic fibroblasts), and peritoneal macrophages of Nrf2 deficient mice. These also showed higher IKK Kinase activity in response to TNF- $\alpha$ or LPS [85]. These studies point to the possible interplay between Nrf2 and NF-kB. It is proposed that these pathways exert an inhibitory effect on each other at the transcription level. The crosstalk can be both ways-Nrf2 inhibition of $\mathrm{NF}-\mathrm{KB}$ and vice versa.

Nrf2 produces a multitude of antioxidant and cytoprotective enzymes in response to oxidative stress [86]. One of them, HO-1 (hemoxygenase-1), is involved in the metabolism of heme by acting as a catalyst in the cleavage of porphyrin ring in heme into

Table 1 A summary of agents targeting the crosstalk between the Nrf2 and NF-kB pathway

\begin{tabular}{|c|c|c|c|}
\hline Drug & Classification & Action & Reference \\
\hline Dexamethasone & Nrf-2 agonist glucocorticoid & $\begin{array}{l}\text { Enhanced I } \kappa \mathrm{B} \text { expression, NF- } \mathrm{kB} \text { retained in the } \\
\text { cellular cytoplasm. }\end{array}$ & {$[95]$} \\
\hline *Remdesivir & Nrf-2 agonist & Reduced dsRNA & {$[96]$} \\
\hline $\mathrm{N}$-acetylcysteine & NF- $\mathrm{kB}$ antagonist, amino acid derivative & Downregulated phosphorylation of IKB & {$[97]$} \\
\hline Dimethyl fumarate & $\begin{array}{l}\text { NF- } k B \text { Antagonist, dimethyl ester of } \\
\text { fumaric acid }\end{array}$ & $\begin{array}{l}\text { Reduced inflammation through Nrf2-dependent and } \\
\text { Nrf2-independent pathways }\end{array}$ & [17] \\
\hline $\begin{array}{l}\text { Epigallocatechin } \\
\text { 3-gallate }\end{array}$ & Nrf-2 Agonist & $\begin{array}{l}\text { Inhibited furin which is a protease enzyme that allows } \\
\text { SARS-CoV-2 S protein's entry inside the cell }\end{array}$ & {$[17]$} \\
\hline 4-Octyl-itaconate & Nrf-2 agonist & Inhibited the release of pro-inflammatory cytokines & [98] \\
\hline Omega 3 fatty acids & NF- $\mathrm{KB}$ antagonist, $\alpha$-linolenic acid & $\begin{array}{l}\text { Decreased inflammatory markers and increased } \\
\text { antioxidant capacity }\end{array}$ & [99] \\
\hline $\begin{array}{l}\text { Soybean } \\
\quad \text { isoflavones }\end{array}$ & $\mathrm{NF}-\mathrm{KB}$ antagonist, flavonoid & $\begin{array}{l}\text { Increased brachial flow-mediated dilation, improved } \\
\text { antioxidant markers }\end{array}$ & {$[79]$} \\
\hline Carnosic Acid & $\mathrm{NF}-\mathrm{kB}$ antagonist, diterpenoids & Reduced spine loss in dendrites, improved memory and learning & {$[100]$} \\
\hline Curcumin & Nrf-2 agonist, diarylheptanoid, & $\begin{array}{l}\text { Antioxidant effect by activated Nrf2 pathway and i } \\
\text { nduced expression of target genes, such as HO-1 and NQO1 }\end{array}$ & [101] \\
\hline Resveratrol & Nrf-2 agonist, Natural polyphenol & Stimulated the Nrf2 signaling by blockage of Keap 1. & {$[102]$} \\
\hline $\begin{array}{l}\text { Bardoxolone } \\
\text { methyl }\end{array}$ & Nrf-2 agonist, semisynthetic triterpenoid & $\begin{array}{l}\text { Protection of cells and tissues from oxidative stress } \\
\text { by increased NRF } 2 \text { transcription }\end{array}$ & [103] \\
\hline Sulfasalazine & $\begin{array}{l}\text { NF- } \kappa \mathrm{B} \text { antagonist, disease-modifying anti- } \\
\text { rheumatic drugs }\end{array}$ & Interfered with I $\kappa \mathrm{B} \alpha$ phosphorylation, inhibited NF- $\mathrm{kB}$ activation & [104] \\
\hline Mesalamine & $\begin{array}{l}\text { Nrf- } 2 \text { agonist, disease-modifying antirheu- } \\
\text { matic drugs }\end{array}$ & Inhibiting posttranslational modifications & [104] \\
\hline Thiophenacetamide & NF- $k B$ antagonist, thiophenes & $\begin{array}{l}\text { Specifically bound to the p65 subunit of the NF- } \mathrm{KB} \\
\text { and inhibited DNA and NF- } \mathrm{kB} \text { binding }\end{array}$ & {$[105]$} \\
\hline Garlic & Nrf-2 agonist & Activated Nrf2-antioxidant response element (ARE) pathway. & {$[106]$} \\
\hline Quercetin & $\mathrm{NF}-\mathrm{\kappa B}$ antagonist, flavonoid & $\begin{array}{l}\text { Inhibited macrophage inflammatory protein } 2, \text { TNF-induced } \\
\text { interferon-gamma-inducible protein }\end{array}$ & [107] \\
\hline Ocimum sanctum & $\mathrm{NF}-\mathrm{kB}$ antagonist & $\begin{array}{l}\text { Inhibited gene expression of cytokines, IL-6, TNF- } \alpha \text {, } \\
\text { MIP- } 1 \alpha, \text { MCP- } 1\end{array}$ & [108] \\
\hline $\begin{array}{l}\text { Hydroxycinnamic } \\
\text { acid }\end{array}$ & NF- $\mathrm{kB}$ antagonist & Inhibited DNA-binding of NF-KB & [104] \\
\hline Niclosamide & Nrf-2 agonist & AMPK-mediated phosphorylated of p62 & [109] \\
\hline Lycopene & $\mathrm{NF}-\mathrm{KB}$ antagonist & Inhibitor of kappa B phosphorylation & {$[110]$} \\
\hline$\beta$-Carotene & NF- $\mathrm{kB}$ antagonist & Scavenges reactive oxygen species & [111] \\
\hline Ritonavir & NF- $\mathrm{kB}$ antagonist & Decreases Akt phosphorylation & [112] \\
\hline Chalcone & Nrf-2 agonist & Induce expression of the Nrf2-dependent enzymes & [113] \\
\hline Ginseng & Nrf-2 agonist & Increases $\mathrm{Nrf2}$ protein expression & {$[114]$} \\
\hline Fenofibrate & Nrf-2 agonist & Activates Nrf2 through p62-dependent Keap1 degradation & {$[115]$} \\
\hline
\end{tabular}

*Although the on-going clinical trials are yet to provide any conclusive evidence in favor of remdesivir. Furthermore, the clinical investigation is desired to substantiate the plausible use of remdesivir as a therapy for COVID-19. US-FDA issued emergency use authorization (FDA) on May 1, 2020 
carbon monoxide, $\mathrm{Fe} 2+$, and biliverdin that converts into bilirubin [87]. A study showed that overexpression of HO-1 in the endothelial cells inhibited TNF- $\alpha$-induced proinflammatory adhesion molecule expression (E-selectin and VCAM-1 (vascular cell adhesion protein 1)). This inhibition was found to be at mRNA level by interfering with the rate of transcription [88]. This represents one way of the crosstalk that the Nrf2 pathway inhibits NF- $\mathrm{kB}$ pathway activation by increasing HO-1 expression, thus reducing the cytokine release. Oxidative stress also causes IKK (IкB kinase) activation that further phosphorylates I $\kappa B$ which is the inhibitor of NF- $\kappa B$ and causes polyubiquitination mediated proteasomal degradation that releases NF-KB. It migrates to the nucleus and leads to the transcription of inflammatory genes. Nrf2 pathway inhibits degradation of IkB- $\alpha$ that leads to its stabilization and inhibition of NF$\kappa \mathrm{B}-\mathrm{mediated}$ transcription. Hence, the release of proinflammatory cytokines is inhibited [86].

NF- $\mathrm{KB}$ can also regulate Nrf2 mediated ARE (antioxidant response element) expression. ARE is the site of the genome for the action of Nrf2. p65, that is the canonical NF-KB subunit can exert an inhibitory effect on the gene expression through ARE [87]. CBP (CREB binding protein)-p300 complex is the transcriptional co-activator of $\mathrm{Nrf} 2$ that has intrinsic histone acetyltransferase activity. This causes histone acetylation and loosens the chromatin structure, thus DNA is exposed for transcriptional activity [87]. A study showed that NF-KB/p65 antagonizes the Nrf2-ARE pathway by reducing ARE gene transcription, decrease in CBP, and enhancing the recruitment of HDAC3 (histone deacetylase 3 ) to the ARE region [89]. This strengthens the view that NF- $\mathrm{KB}$ activation suppresses the Nrf2 pathway in case of enhanced oxidative stress or cytokine storm

Keap1, with which Nrf2 exists in bound form in the cytoplasm, has been found to negatively regulate IKK $\beta$. HSP90 (heat shock protein 90) is a chaperone protein that assists in protein folding. It has been observed that Keapl prevents the binding of HSP90 to IKK $\beta$ which is the trigger for its autophagic degradation. Also, Keap 1 reduces IKK $\beta$ phosphorylation by concealing those residues that bind with the phosphate groups. The result of this entire interaction is that $\operatorname{I\kappa B}-\alpha$ is stabilized because IKK $\beta$ is not phosphorylated that, as a result, reduces NF- $\mathrm{BB}$ signaling [87, 90]. Figure 5 represents crosstalk between NF- $\mathrm{KB}$ and Nrf2 pathways mediated by COVID-19 infection leading to neurological complications.

Patients with pre-existing auto-immune disorder susceptibility are at grave risk for COVID-19. Due to the administration of immunosuppressant for mitigating the virus, the interest in auto-immunity is implied [91]. The dysfunctional regulatory $\mathrm{T}$ cells have been regarded as the cause of many autoimmune disorders. When Nrf2 is systemically activated by Keap1 (Kelch-like ECH-associated protein 1), tissue inflammation is enhanced. On the other hand, its knockdown reduces $\mathrm{T}$ cell and cytokine production. Nrf2 induction can mitigate the regulatory $\mathrm{T}$ cell dysfunction and alleviate autoimmune disorders especially, in the case of COVID-19 where the latter is further stressed upon [92]. NF- $\kappa \mathrm{B}$ has a role in promoting inflammation in autoimmune attacks as well as mediating immunogenic tolerance. It promotes the formation of regulatory $\mathrm{T}$ cells and plays a role in deleting self-reacting $\mathrm{T}$ cells situated in the thymus. The NF-KB thus lies centrally in preserving immune homeostasis and prevention of autoimmunity caused in COVID-19 [93].

\section{Various Modulators with Action on NF-KB and Nrf2 Pathways}

COVID-19 is characterized by a cytokine storm due to the attack on the patient's immune cells. The mainstay of treatment is the use of anti-viral agents. Immunomodulatory agents both synthetic and herbal can be pertinent in catering and
Fig. 6 Promising modulating agents against COVID-19

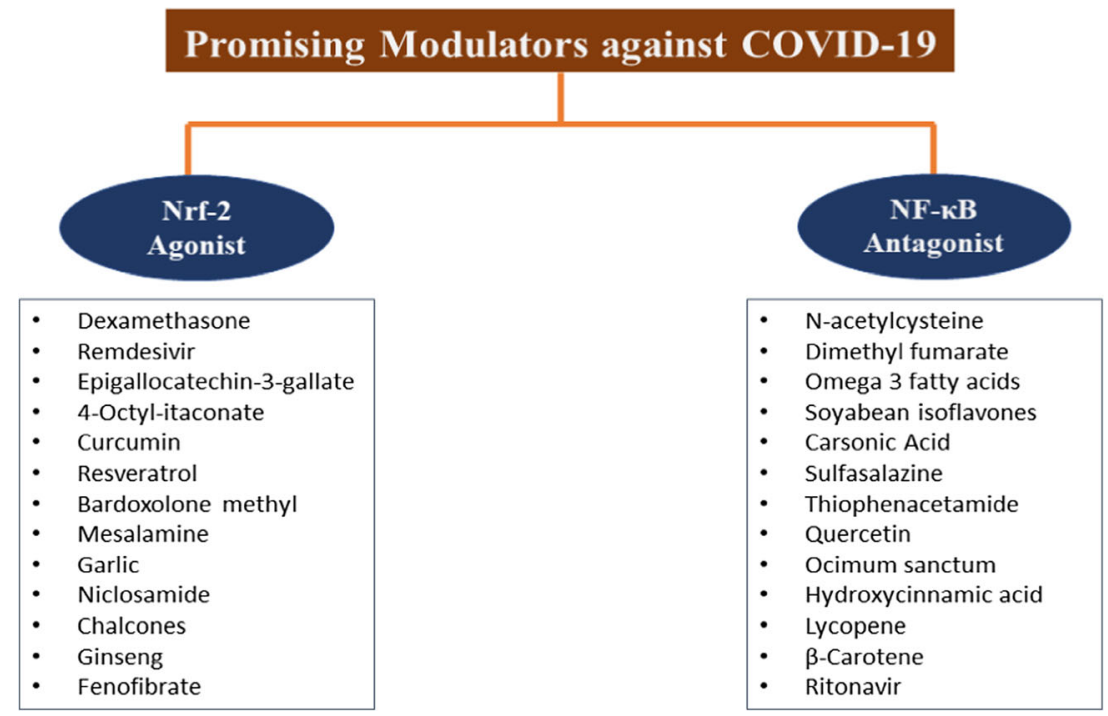


resolving the serious effects of the attack of the virus. These immunomodulatory agents act in synergism with the preexisting approaches and act as adjunctive therapy or prophylaxis [94]. The Nrf2 and NF-KB pathway are involved in the development and progress of inflammatory pathology in COVID-19. Consequently, immunomodulators targeting the crosstalk between these key signaling pathways offer an innovative approach in tackling this deadly pandemic and present a ray of shine in tackling COVID-19 associated neurological complications. Table 1 presents a comprehensive summary of agents targeting the crosstalk between the Nrf2 and NF-KB pathways. Figure 6 presents promising modulating agents against COVID-19.

\section{Perspectives and Conclusion}

COVID-19 received the status of a pandemic on March 11, 2020 , by WHO. Since its first case in Wuhan, China in December 2019, the disease has come a long way, with the number of cases and the number of deaths surging daily. Oxidative stress and inflammatory cytokine storm are key characteristics of the pathology concerning this deadly virus. Many studies discussed point the substantial body of evidence hinting at severe neurological complications in patients. Various drugs have been repurposed to cater to the emergent need for therapeutics. The development and early approval of vaccines have been fast-tracked all around the globe. While the citizens of the globe await an efficacious vaccine, there is a dire need for innovative therapeutic approaches to cater to this deadly disorder. Crosstalk between both, NF-KB and Nrf2 signaling pathway lies at the center of neurological complications in COVID-19 patients. Immuno-modulators both synthetic and natural can be promising candidates in catering to the pathologies targeted in the aforementioned pathways. Immunomodulatory agents act in synergism with the preexisting approaches and act as adjunctive therapy or prophylaxis and outstand existing approaches by specifically targeting the oxidative stress and consequently, eradicating and undermining the pathology leading to severe neurological disorders.

Data Availability of Data and Material It's a review article. Hence, all the material has been provided.

Authors' Contributions RB \& AK conceived and designed the article. GK \& DK did the literature search using various databases. RB, GK, and DK wrote the manuscript. AK approved and revised the final draft.

\section{Declarations}

Conflict of interest The authors declare that they have no conflict of interest.
Consent to Publication All authors have agreed upon the final version of the article before submission and their consent has been sought.

\section{References}

1. Park SE (2020) Epidemiology, virology, and clinical features of severe acute respiratory syndrome coronavirus 2 (SARS-CoV-2; coronavirus disease-19). Pediatr Infect Vaccine 27:1-10. https:// doi.org/10.14776/piv.2020.27.e9

2. Paraskevis D, Kostaki EG, Magiorkinis G, Panayiotakopoulos G, Sourvinos G, Tsiodras S (2020) Full-genome evolutionary analysis of the novel corona virus (2019-nCoV) rejects the hypothesis of emergence as a result of a recent recombination event. Infect Genet Evol 79:104212. https://doi.org/10.1016/j.meegid.2020. 104212

3. Gorbalenya AE, Baker SC, Baric RS et al (2020) The species severe acute respiratory syndrome-related coronavirus: classifying 2019-nCoV and naming it SARS-CoV-2. Nat Microbiol 5:536544. https://doi.org/10.1038/s41564-020-0695-Z

4. WHO Director-General's opening remarks at the media briefing on COVID-19 - 11 March 2020

5. Leonardi M, Padovani A, McArthur JC (2020) Neurological manifestations associated with COVID-19: a review and a call for action. J. Neurol. 267:1573-1576

6. Gklinos P (2020) Neurological manifestations of COVID-19: a review of what we know so far. J. Neurol. 267:2485-2489

7. Wu Y, Xu X, Chen Z, Duan J, Hashimoto K, Yang L, Liu C, Yang C (2020) Brain, behavior, and immunity nervous system involvement after infection with COVID-19 and other coronaviruses. Brain Behav Immun 87:18-22. https://doi.org/10.1016/j.bbi. 2020.03.031

8. Mao L, Wang M, Chen S, He Q, Chang J, Hong C, Zhou Y, Wang $D$ et al (2020) Neurological manifestations of hospitalized patients with COVID-19 in Wuhan, China: a retrospective case series study. SSRN Electron J. https://doi.org/10.2139/ssrn.3544840

9. Pinna P, Grewal P, Hall JP, Tavarez T, Dafer RM, Garg R, Osteraas ND, Pellack DR et al (2020) Neurological manifestations and COVID-19: experiences from a tertiary care center at the frontline. J Neurol Sci 415:116969. https://doi.org/10.1016/j.jns. 2020.116969

10. Varatharaj A, Thomas N, Ellul MA, Davies NWS, Pollak TA, Tenorio EL, Sultan M, Easton A et al (2020) Neurological and neuropsychiatric complications of COVID-19 in 153 patients: a UK-wide surveillance study. The Lancet Psychiatry 7:875-882. https://doi.org/10.1016/S2215-0366(20)30287-X

11. Khatoon F, Prasad K, Kumar V (2020) Neurological manifestations of COVID-19: available evidences and a new paradigm. J Neurovirol 26:619-630. https://doi.org/10.1007/s13365-02000895-4

12. Huang C, Wang Y, Li X, Ren L, Zhao J, Hu Y, Zhang L, Fan G et al (2020) Clinical features of patients infected with 2019 novel coronavirus in Wuhan, China. Lancet 395:497-506. https://doi. org/10.1016/S0140-6736(20)30183-5

13. Qin C, Zhou L, Hu Z, Zhang S, Yang S, Tao Y, Xie C, Ma K et al (2020) Dysregulation of immune response in patients with coronavirus 2019 (COVID-19) in Wuhan, China. Clin Infect Dis 71: 762-768. https://doi.org/10.1093/cid/ciaa248

14. Chen G, Wu D, Guo W, Cao Y, Huang D, Wang H, Wang T, Zhang X et al (2020) Clinical and immunological features of severe and moderate coronavirus disease 2019. J Clin Invest 130: 2620-2629. https://doi.org/10.1172/JCI137244

15. Sohn KM, Lee S-G, Kim HJ, Cheon S, Jeong H, Lee J, Kim IS, Silwal P et al (2020) COVID-19 patients upregulate toll-like receptor 4-mediated inflammatory signaling that mimics bacterial 
sepsis. J Korean Med Sci 35:e343. https://doi.org/10.3346/jkms. 2020.35.e343

16. Liu T, Zhang L, Joo D, Sun SC (2017) NF-kB signaling in inflammation. Signal Transduct. Target. Ther. 2:17023

17. Zinovkin RA, Grebenchikov OA (2020) Transcription factor Nrf2 as a potential therapeutic target for prevention of cytokine storm in COVID-19 patients. Biochem 85:833-837. https://doi.org/10. 1134/S0006297920070111

18. Olagnier D, Farahani E, Thyrsted J, Blay-Cadanet J, Herengt A, Idorn M, Hait A, Hernaez B et al (2020) SARS-CoV2-mediated suppression of NRF2-signaling reveals potent antiviral and anti-inflammatory activity of 4-octyl-itaconate and dimethyl fumarate. Nat Commun 11: 1-12. https://doi.org/10.1038/s41467-020-18764-3

19. McCord JM, Hybertson BM, Cota-Gomez A et al (2020) Nrf2 activator pb125® as a potential therapeutic agent against covid19. Antioxidants 9:1-15. https://doi.org/10.3390/antiox9060518

20. Tian Y, Wang W, Xu L, Li H, Wei Y, Wu Q, Jia J (2019) Activation of Nrf2/ARE pathway alleviates the cognitive deficits in PS1V97L-Tg mouse model of Alzheimer's disease through modulation of oxidative stress. J Neurosci Res 97:492-505. https://doi.org/10.1002/jnr.24357

21. Astuti I, Ysrafil (2020) Severe Acute Respiratory Syndrome Coronavirus 2 (SARS-CoV-2): an overview of viral structure and host response. Diabetes Metab Syndr Clin Res Rev 14:407412. https://doi.org/10.1016/j.dsx.2020.04.020

22. Mousavizadeh L, Ghasemi S (2020) Genotype and phenotype of COVID-19: their roles in pathogenesis. J Microbiol Immunol Infect. https://doi.org/10.1016/j.jmii.2020.03.022

23. Ulrich H, Pillat MM (2020) CD147 as a target for COVID-19 treatment: suggested effects of azithromycin and stem cell engagement. Stem Cell Rev Reports 16:434-440. https://doi.org/10. 1007/s12015-020-09976-7

24. Wang K, Chen W, Zhang Z, Deng Y, Lian JQ, du P, Wei D, Zhang Y et al (2020) CD147-spike protein is a novel route for SARS-CoV-2 infection to host cells. Signal Transduct Target Ther 5:1-10. https://doi.org/10.1038/s41392-020-00426-x

25. Daly JL, Simonetti B, Antón-Plágaro C et al (2020) Neuropilin-1 is a host factor for SARS-CoV-2 infection. bioRxiv 865:861-865. https://doi.org/10.1101/2020.06.05.134114

26. Cantuti-Castelvetri L, Ojha R, Pedro LD et al (2020) Neuropilin-1 facilitates SARS-CoV-2 cell entry and infectivity. Science (80-) 370:856-860. https://doi.org/10.1126/science.abd2985

27. Moutal A, Martin LF, Boinon L, Gomez K, Ran D, Zhou Y, Stratton HJ, Cai S et al (2021) SARS-CoV-2 spike protein coopts VEGF-A/neuropilin-1 receptor signaling to induce analgesia. Pain 162:243-252. https://doi.org/10.1097/j.pain. 0000000000002097

28. Wang D, Hu B, Hu C, Zhu F, Liu X, Zhang J, Wang B, Xiang H et al (2020) Clinical characteristics of 138 hospitalized patients with 2019 novel coronavirus-infected pneumonia in Wuhan, China. JAMA - J Am Med Assoc 323:1061-1069. https://doi. org/10.1001/jama.2020.1585

29. Chen N, Zhou M, Dong X, Qu J, Gong F, Han Y, Qiu Y, Wang J et al (2020) Epidemiological and clinical characteristics of 99 cases of 2019 novel coronavirus pneumonia in Wuhan, China: a descriptive study. Lancet 395:507-513. https://doi.org/10.1016/ S0140-6736(20)30211-7

30. Nepal G, Rehrig JH, Shrestha GS, Shing YK, Yadav JK, Ojha R, Pokhrel G, Tu ZL et al (2020) Neurological manifestations of COVID-19: a systematic review. Crit Care 24:1-11. https://doi. org/10.1186/s13054-020-03121-z

31. Helms J, Kremer S, Merdji H, Clere-Jehl R, Schenck M, Kummerlen C, Collange O, Boulay C et al (2020) Neurologic features in severe SARS-CoV-2 infection. N Engl J Med 382: 2268-2270. https://doi.org/10.1056/nejmc2008597
32. Chaumont H, San-Galli A, Martino F, Couratier C, Joguet G, Carles M, Roze E, Lannuzel A (2020) Mixed central and peripheral nervous system disorders in severe SARS-CoV-2 infection. J. Neurol. 267:3121-3127

33. Mcloughlin BC, Miles A, Webb TE, Knopp P, Eyres C, Fabbri A, Humphries F, Davis D (2020) Functional and cognitive outcomes after COVID-19 delirium. Eur Geriatr Med 11:857-862. https:// doi.org/10.1007/s41999-020-00353-8

34. Gulko E, Oleksk ML, Gomes W et al (2020) mri brain findings in 126 patients with covid-19: initial observations from a descriptive literature review. Am J Neuroradiol:1-5. https://doi.org/10.3174/ ajnr.a6805

35. Giacomelli A, Pezzati L, Conti F, Bernacchia D, Siano M, Oreni L, Rusconi S, Gervasoni C et al (2020) Self-reported olfactory and taste disorders in patients with severe acute respiratory coronavirus 2 infection: a cross-sectional study. Clin. Infect. Dis. 71:889890

36. (OMS) WHO (2020) COVID-19 Weekly Epidemiological Update. November 1;4

37. (OMS) WHO (2020) COVID-19 Weekly Epidemiological Update. December 1;4

38. WHO Coronavirus Disease (COVID-19) Dashboard | WHO Coronavirus Disease (COVID-19) Dashboard

39. Abate BB, Kassie AM, Kassaw MW et al (2020) Sex difference in coronavirus disease (COVID-19): a systematic review and metaanalysis. BMJ Open 10:40129

40. Jin J-M, Bai P, He W, Wu F, Liu XF, Han DM, Liu S, Yang JK (2020) Gender differences in patients with COVID-19: focus on severity and mortality. Front Public Heal 8:152. https://doi.org/10. 3389/fpubh.2020.00152

41. Griffith DM, Sharma G, Holliday CS, Enyia OK, Valliere M, Semlow AR, Stewart EC, Blumenthal RS (2020) Men and COVID-19: a biopsychosocial approach to understanding sex differences in mortality and recommendations for practice and policy interventions. Prev Chronic Dis 17:200247. https://doi.org/10. 5888/pcd17.200247

42. Ge H, Wang X, Yuan X et al (2020) The epidemiology and clinical information about. COVID-19 39(6):1011-1019

43. Singhal T (2020) Review on COVID19 disease so far. Indian J Pediatr 87:281-286

44. Yan R, Zhang Y, Li Y et al (2020) Structural basis for the recognition of SARS-CoV-2 by full-length human ACE2. Science (80) 367:1444-1448. https://doi.org/10.1126/science.abb2762

45. Yang J, Petitjean SJL, Koehler M, Zhang Q, Dumitru AC, Chen W, Derclaye S, Vincent SP et al (2020) Molecular interaction and inhibition of SARS-CoV-2 binding to the ACE2 receptor. Nat Commun 11:1-21. https://doi.org/10.1038/s41467-020-18319-6

46. Hamming I, Timens W, Bulthuis MLC, Lely AT, Navis GJ, van Goor H (2004) Tissue distribution of ACE2 protein, the functional receptor for SARS coronavirus. A first step in understanding SARS pathogenesis. J Pathol 203:631-637. https://doi.org/10. 1002/path. 1570

47. Parasher A (2020) COVID-19: Current understanding of its pathophysiology, clinical presentation and treatment. Postgrad Med J postgradmedj-2020-138577. https://doi.org/10.1136/ postgradmedj-2020-138577

48. Mason RJ (2020) Pathogenesis of COVID-19 from a cell biology perspective. Eur Respir J 55:9-11. https://doi.org/10.1183/ 13993003.00607-2020

49. Smith JC, Ellenberger HH, Ballanyi K et al (1991) Pre-Bötzinger complex: a brainstem region that may generate respiratory rhythm in mammals. Science (80- ) 254:726-729. https://doi.org/10.1126/ science. 1683005

50. Burgold T, Spreafico F, De Santa F et al (2008) The histone H3 lysine 27 -specific demethylase Jmjd3 is required for neural 
commitment. PLoS One 3(8):e3034. https://doi.org/10.1371/ journal.pone. 0003034

51. Li Y, Li M, Wang M, Zhou Y, Chang J, Xian Y, Wang D, Mao L et al (2020) Acute cerebrovascular disease following COVID-19: a single center, retrospective, observational study. Stroke Vasc Neurol 5:279-284. https://doi.org/10.1136/svn-2020-000431

52. Alonso-Lana S, Marquié M, Ruiz A, Boada M (2020) Cognitive and neuropsychiatric manifestations of COVID-19 and effects on elderly individuals with dementia. Front. Aging Neurosci. 12: 588872

53. Bolay H, Gül A, Baykan B (2020) COVID-19 is a real headache! Headache 60:1415-1421. https://doi.org/10.1111/head.13856

54. Lodigiani C, Iapichino G, Carenzo L, Cecconi M, Ferrazzi P, Sebastian T, Kucher N, Studt JD et al (2020) Venous and arterial thromboembolic complications in COVID-19 patients admitted to an academic hospital in Milan, Italy. Thromb Res 191:9-14. https://doi.org/10.1016/j.thromres.2020.04.024

55. Hess DC, Eldahshan W, Rutkowski E (2020) COVID-19-related stroke. Transl. Stroke Res. 11:322-325

56. Sharifi-Razavi A, Karimi N, Rouhani N (2020) COVID-19 and intracerebral haemorrhage: causative or coincidental? New Microbes New Infect 35:100669. https://doi.org/10.1016/j.nmni. 2020.100669

57. Sharifian-Dorche M, Huot P, Osherov M, Wen D, Saveriano A, Giacomini PS, Antel JP, Mowla A (2020) Neurological complications of coronavirus infection; a comparative review and lessons learned during the COVID-19 pandemic. J. Neurol. Sci. 417: 117085

58. Zhao K, Huang J, Dai D et al (2020) Acute myelitis after SARSCoV-2 infection: a case report. medRxiv 2020.03.16.20035105. https://doi.org/10.1101/2020.03.16.20035105

59. Moriguchi T, Harii N, Goto J, Harada D, Sugawara H, Takamino J, Ueno M, Sakata H et al (2020) A first case of meningitis/ encephalitis associated with SARS-Coronavirus-2. Int J Infect Dis 94:55-58. https://doi.org/10.1016/j.ijid.2020.03.062

60. Garg R (2020) Spectrum of neurological manifestations in Covid19: a review. Neurol India 68:560-572. https://doi.org/10.4103/ 0028-3886.289000

61. Radmanesh A, Derman A, Lui YW, Raz E, Loh JP, Hagiwara M, Borja MJ, Zan E et al (2020) COVID-19-associated diffuse leukoencephalopathy and microhemorrhages. Radiology 297: E223-E227. https://doi.org/10.1148/radiol.2020202040

62. Virhammar J, Kumlien E, Fällmar D, Frithiof R, Jackmann S, Sköld MK, Kadir M, Frick J et al (2020) Acute necrotizing encephalopathy with SARS-CoV-2 RNA confirmed in cerebrospinal fluid. Neurology 95:445-449. https://doi.org/10.1212/WNL. 0000000000010250

63. Elgamasy S, Kamel MG, Ghozy S, Khalil A, Morra ME, Islam SMS (2020) First case of focal epilepsy associated with SARScoronavirus-2. J Med Virol 92:2238-2242. https://doi.org/10. $1002 / j m v .26113$

64. Hepburn M, Mullaguri N, George P, Hantus S, Punia V, Bhimraj A, Newey CR (2020) acute symptomatic seizures in critically ill patients with COVID-19: is there an association? Neurocrit Care 28:1-5. https://doi.org/10.1007/s12028-020-01006-1

65. Asadi-Pooya AA (2020) Seizures associated with coronavirus infections. Seizure 79:49-52

66. Zhou H, Lu S, Chen J, Wei N, Wang D, Lyu H, Shi C, Hu S (2020) The landscape of cognitive function in recovered COVID-19 patients. J Psychiatr Res 129:98-102. https://doi.org/ 10.1016/j.jpsychires.2020.06.022

67. Zubair AS, McAlpine LS, Gardin T et al (2020) Neuropathogenesis and neurologic manifestations of the coronaviruses in the age of coronavirus disease 2019: A review. JAMA Neurol. 77:1018-1027
68. Hawkes CH (2020) Smell, taste and Covid-19: testing is essential. QJM An Int J Med:1-9. https://doi.org/10.1093/qjmed/hcaa326

69. Madia F, Merico B, Primiano G, Cutuli SL, de Pascale G, Servidei S (2020) Acute myopathic quadriplegia in patients with COVID19 in the intensive care unit. Neurology 95:492-494. https://doi. org/10.1212/WNL.0000000000010280

70. Tankisi H, Tankisi A, Harbo T, Markvardsen LK, Andersen H, Pedersen TH (2020) Critical illness myopathy as a consequence of Covid-19 infection. Clin. Neurophysiol. 131:1931-1932

71. Gutierrez H, Davies AM (2011) Regulation of neural process growth, elaboration and structural plasticity by NF-I ${ }^{\circ} \mathrm{B}$. Trends Neurosci 34:316-325. https://doi.org/10.1016/j.tins.2011.03.001

72. Kopitar-Jeraia N (2015) Innate immune response in brain, nfkappa $\mathrm{b}$ signaling and cystatins. Front. Mol. Neurosci. 8:73

73. Shih RH, Wang CY, Yang CM (2015) NF-kappaB signaling pathways in neurological inflammation: a mini review. Front. Mol. Neurosci. 8:77

74. Montalvan V, Lee J, Bueso T, de Toledo J, Rivas K (2020) Neurological manifestations of COVID-19 and other coronavirus infections: a systematic review. Clin. Neurol. Neurosurg. 194: 105921

75. Guisado-Vasco P, Cano-Megías M, Rodríguez-López M, deLuna-Boquera IM, Carnevali-Ruiz D, Immunosuppressants Against COVID-19 Working Team (2020) COVID-19 and metabolic syndrome: NF-KB activation. Crossroads. Trends Endocrinol. Metab. 31:802-803

76. DeDiego ML, Nieto-Torres JL, Regla-Nava JA et al (2014) Inhibition of NF- B-mediated inflammation in severe acute respiratory syndrome coronavirus-infected mice increases survival. J Virol 88:913-924. https://doi.org/10.1128/jvi.02576-13

77. Welcome MO, Precision T (2020) Neuropathophysiology of coronavirus disease 2019: neuroinflammation and blood brain barrier disruption are critical pathophysiological processes that contribute to the clinical symptoms of Sars-Cov2 infection. Inflammopharmacology (pre-print)

78. Hassan SM, Jawad MJ, Ahjel SW et al (2020) The Nrf2 Activator (DMF) and Covid-19: is there a possible role? Med. Arch. (Sarajevo, Bosnia Herzegovina) 74:134-138

79. Brandes MS, Gray NE (2020) NRF2 as a therapeutic target in neurodegenerative diseases. ASN Neuro 88(Pt B):253-267. https://doi.org/10.1177/1759091419899782

80. Ramsey CP, Glass CA, Montgomery MB, Lindl KA, Ritson GP, Chia LA, Hamilton RL, Chu CT et al (2007) Expression of Nrf2 in neurodegenerative diseases. J Neuropathol Exp Neurol 66:75-85. https://doi.org/10.1097/nen.0b013e31802d6da9

81. Sun Z, Huang Z, Zhang DD (2009) Phosphorylation of Nrf2 at multiple sites by MAP kinases has a limited contribution in modulating the Nrf2-dependent antioxidant response. PLoS One 4: 6588. https://doi.org/10.1371/journal.pone.0006588

82. Zipper LM (2003) Erk activation is required for Nrf2 nuclear localization during pyrrolidine dithiocarbamate induction of glutamate cysteine ligase modulatory gene expression in HepG2 cells. Toxicol Sci 73:124-134. https://doi.org/10.1093/toxsci/ kfg083

83. Cecchini R, Cecchini AL (2020) SARS-CoV-2 infection pathogenesis is related to oxidative stress as a response to aggression. Med Hypotheses 143:110102. https://doi.org/10.1016/j.mehy. 2020.110102

84. Pan H, Wang H, Wang X, Zhu L, Mao L (2012) The absence of Nrf2 enhances NF-KB-dependent inflammation following scratch injury in mouse primary cultured astrocytes. Mediators Inflamm 2012:217580-217589. https://doi.org/10.1155/2012/217580

85. Thimmulappa RK, Lee H, Rangasamy T, Reddy SP, Yamamoto M, Kensler TW, Biswal S (2006) Nrf2 is a critical regulator of the innate immune response and survival during experimental sepsis. J Clin Invest 116:984-995. https://doi.org/10.1172/JCI25790 
86. Ganesh Yerra V, Negi G, Sharma SS, Kumar A (2013) Potential therapeutic effects of the simultaneous targeting of the Nrf2 and NF-KB pathways in diabetic neuropathy. Redox Biol. 1:394-397

87. Wardyn JD, Ponsford AH, Sanderson CM (2015) Dissecting molecular cross-talk between Nrf2 and NF-KB response pathways. Biochem Soc Trans 43:621-626. https://doi.org/10.1042/ BST20150014

88. Soares MP, Seldon MP, Gregoire IP, Vassilevskaia T, Berberat PO, Yu J, Tsui TY, Bach FH (2004) Heme oxygenase-1 modulates the expression of adhesion molecules associated with endothelial cell activation. J Immunol 172:3553-3563. https://doi.org/ 10.4049/jimmunol.172.6.3553

89. Liu G-H, Qu J, Shen X (2008) NF-kB/p65 antagonizes Nrf2-ARE pathway by depriving CBP from Nrf2 and facilitating recruitment of HDAC3 to MafK. Biochim Biophys Acta - Mol Cell Res 1783: 713-727. https://doi.org/10.1016/J.BBAMCR.2008.01.002

90. Kim JE, You DJ, Lee C, Ahn C, Seong JY, Hwang JI (2010) Suppression of NF-kB signaling by KEAP1 regulation of IKK $\beta$ activity through autophagic degradation and inhibition of phosphorylation. Cell Signal 22:1645-1654. https://doi.org/10.1016/j. cellsig.2010.06.004

91. Druyan A, Lidar M, Brodavka M, Levy I, Barzilai A, Pavlotsky F (2021) The risk for severe COVID- 19 in patients with autoimmune and/or inflammatory diseases: first wave lessons. Dermatol Ther 34:e14627. https://doi.org/10.1111/dth.14627

92. Suzuki T, Murakami S, Biswal SS, Sakaguchi S, Harigae H, Yamamoto M, Motohashi H (2017) Systemic activation of NRF2 alleviates lethal autoimmune inflammation in scurfy mice. Mol Cell Biol 37:e00063-e00017. https://doi.org/10.1128/MCB. 00063-17

93. Sun SC, Chang JH, Jin J (2013) Regulation of nuclear factor- $\mathrm{kB}$ in autoimmunity. Trends Immunol. 34:282-289

94. Bhandari R, Khanna G, Kuhad A (2020) Pharmacological insight into potential therapeutic agents for the deadly Covid-19 pandemic. Eur J Pharmacol 890:173643. https://doi.org/10.1016/j.ejphar. 2020.173643

95. Hariharan A, Hakeem AR, Radhakrishnan S et al (2020) The role and therapeutic potential of NF-kappa-B pathway in severe COVID-19 patients. Inflammopharmacology 1:3

96. Beigel JH, Tomashek KM, Dodd LE, Mehta AK, Zingman BS, Kalil AC, Hohmann E, Chu HY et al (2020) Remdesivir for the treatment of Covid-19 - final report. N Engl J Med 383:18131826. https://doi.org/10.1056/nejmoa2007764

97. Oka SI, Kamata H, Kamata K, Yagisawa H, Hirata H (2000) NAcetylcysteine suppresses TNF-induced NF- $\mathrm{KB}$ activation through inhibition of IKB kinases. FEBS Lett 472:196-202. https://doi.org/10.1016/S0014-5793(00)01464-2

98. Olagnier D, Farahani E, Thyrsted J et al (2020) SARS-CoV2mediated suppression of NRF2-signaling reveals potent antiviral and anti-inflammatory activity of 4-octyl-itaconate and dimethyl fumarate. Nat Commun 11(1):4938

99. Gallai V, Sarchielli P, Trequattrini A, Franceschini M, Floridi A, Firenze C, Alberti A, di Benedetto D et al (1995) Cytokine secretion and eicosanoid production in the peripheral blood mononuclear cells of MS patients undergoing dietary supplementation with n-3 polyunsaturated fatty acids. J Neuroimmunol 56:143153. https://doi.org/10.1016/0165-5728(94)00140-J

100. Dinkova-Kostova AT, Kostov RV, Kazantsev AG (2018) The role of $\mathrm{Nrf} 2$ signaling in counteracting neurodegenerative diseases. FEBS J. 285:3576-3590

101. Serafini MM, Catanzaro M, Fagiani F, Simoni E, Caporaso R, Dacrema M, Romanoni I, Govoni S et al (2020) Modulation of Keap1/Nrf2/ARE signaling pathway by curcuma- and garlicderived hybrids. Front Pharmacol 10:1597. https://doi.org/10. 3389/fphar.2019.01597
102. Farkhondeh T, Folgado SL, Pourbagher-Shahri AM, Ashrafizadeh M, Samarghandian S (2020) The therapeutic effect of resveratrol: focusing on the Nrf2 signaling pathway. Biomed Pharmacother 127:110234. https://doi.org/10.1016/j.biopha. 2020.110234

103. Borella R, Forti L, Gibellini L, de Gaetano A, de Biasi S, Nasi M, Cossarizza A, Pinti M (2019) Synthesis and anticancer activity of CDDO and CDDO-me, two derivatives of natural triterpenoids. Molecules 24(22):4097

104. Herrington FD, Carmody RJ, Goodyear CS (2016) Modulation of $\mathrm{NF}-\mathrm{KB}$ signaling as a therapeutic target in autoimmunity. $\mathrm{J}$. Biomol. Screen. 21:223-242

105. Silva VS, Vergara FM, Seito LN, Antunes D, Santos LHS, Henriques MG, Caffarena ER (2019) Thiophenacetamide as a potential modulator to NF-kB: structure and dynamics study using in silico and molecular biology assays. J Biomol Struct Dyn 37: 4395-4406. https://doi.org/10.1080/07391102.2018.1552623

106. Eudy BJ, Carter RE, Abed SA et al Activation of Nrf2 target genes by aged garlic extract in THP-1 macrophages: regulation by glutathione depletion. FASEB J 31:974.24-974.24. https://doi.org/10. 1096/FASEBJ.31.1_SUPPLEMENT.974.24

107. Ruiz PA, Braune A, Hölzlwimmer G et al (2007) Quercetin inhibits TNF-induced NF- $\mathrm{KB}$ transcription factor recruitment to proinflammatory gene promoters in murine intestinal epithelial cells. J Nutr 137:1208-1215. https://doi.org/10.1093/jn/137.5.1208

108. Choudhury SS, Bashyam L, Manthapuram N, Bitla P, Kollipara P, Tetali SD (2014) Ocimum sanctum leaf extracts attenuate human monocytic (THP-1) cell activation. J Ethnopharmacol 154:148155. https://doi.org/10.1016/j.jep.2014.03.049

109. Park JS, Lee YS, Lee DH, Bae SH (2019) Repositioning of niclosamide ethanolamine (NEN), an anthelmintic drug, for the treatment of lipotoxicity. Free Radic Biol Med 137:143-157. https://doi.org/10.1016/j.freeradbiomed.2019.04.030

110. Assar EA, Vidalle MC, Chopra M, Hafizi S (2016) Lycopene acts through inhibition of IKB kinase to suppress NF- $\mathrm{KB}$ signaling in human prostate and breast cancer cells. Tumor Biol 37:93759385. https://doi.org/10.1007/s13277-016-4798-3

111. Cho SO, Kim M-H, Kim H (2018) $\beta$-Carotene inhibits activation of NF- $\mathrm{KB}$, activator protein-1, and STAT3 and regulates abnormal expression of some adipokines in 3 T3-L1 Adipocytes. J Cancer Prev 23:37-43. https://doi.org/10.15430/jcp.2018.23.1.37

112. Pati S, Nguyen A, Foulke JS, Weichold F, Reitz M (2005) Ritonavir inhibits NF-AT activation through effects on the PI-3 kinase/Akt pathway. Retrovirology 2:1-1. https://doi.org/10. 1186/1742-4690-2-S1-S44

113. Kim HJ, Jang BK, Park JH, Choi JW, Park SJ, Byeon SR, Pae AN, Lee YS et al (2020) A novel chalcone derivative as Nrf2 activator attenuates learning and memory impairment in a scopolamineinduced mouse model. Eur J Med Chem 185:111777. https://doi. org/10.1016/j.ejmech.2019.111777

114. Li J, Ichikawa T, Jin Y, Hofseth LJ, Nagarkatti P, Nagarkatti M, Windust A, Cui T (2010) An essential role of Nrf2 in American ginseng-mediated anti-oxidative actions in cardiomyocytes. J Ethnopharmacol 130:222-230. https://doi.org/10.1016/j.jep. 2010.03.040

115. Park JS, Kang DH, Lee DH, Bae SH (2015) Fenofibrate activates Nrf2 through p62-dependent Keap1 degradation. Biochem Biophys Res Commun 465:542-547. https://doi.org/10.1016/j. bbrc.2015.08.056

Publisher's Note Springer Nature remains neutral with regard to jurisdictional claims in published maps and institutional affiliations. 